\title{
Instruções e Iniqüidade de Reforços: Efeitos Sobre o Comportamento Competitivo ${ }^{1}$
}

\author{
Josele Abreu-Rodrigues ${ }^{2}$, Paula Carvalho Natalino e Raquel Moreira Aló \\ Universidade de Brasília
}

\begin{abstract}
RESUMO - O presente estudo investigou se a precisão da instrução afetaria os efeitos da iniqüidade de reforços. Trinta estudantes universitários, separados em duplas, escolheram entre trabalhar sozinho ou competir com o parceiro. Na alternativa individual, os pontos foram distribuídos igualmente entre os participantes; na alternativa de competição, a distribuição de pontos foi manipulada no decorrer das condições de modo que o Participante 1 ganhava mais pontos que o Participante 2, ou vice-versa. Algumas duplas receberam informação completa sobre a distribuição de pontos (instrução precisa); outras receberam informação indicando que, algumas vezes, um participante receberia mais pontos que o outro (instrução imprecisa); e, as demais, não receberam nenhuma informação (sem instrução). A instrução imprecisa produziu escolha acentuada por competição para ambos participantes, a instrução precisa gerou escolhas sensíveis às manipulações na iniqüidade e, na ausência de instruções, ambos resultados foram observados. Foi concluído que a instrução precisa gerou estratégias mais eficientes de fuga e esquiva da iniqüidade.
\end{abstract}

Palavras-chave: competição; instrução; iniqüidade.

\section{Instructions and Inequity Between Reinforcers: Effects Upon Competitive Behavior}

\begin{abstract}
The present study investigated whether the precision of instructions alter the effects of reinforcement inequity. Thirty university students, separated in dyads, chose between working alone or competing with their partner. During the individual alternative, points were distributed equally between participants; during the competitive alternative, points distribution was manipulated across conditions such that Participant 1 received a greater number of points than Participant 2, and viceversa. The dyads received complete information on points distribution (precise instruction group), vague information indicating only that sometimes one participant would win more points than the other (imprecise instruction group), or no information about points distribution (no instruction group). Imprecise instruction produced an accentuated choice for competition for both participants while the precise instruction generated choices that changed with manipulations in inequity. In the absence of instructions, both results were observed. It was concluded that precise instruction generated more efficient strategies of escape and avoidance from inequity.
\end{abstract}

Key words: competition; instruction; inequity.

$\mathrm{Na}$ abordagem analítico-comportamental, comportamento social refere-se a processos comportamentais em que os estímulos motivacionais, discriminativos ou reforçadores são originados ou mediados pelo comportamento de outro organismo (Keller \& Schoenfeld, 1950/1971). Nas situações sociais que têm como objetivo a execução de tarefas, tipos diversos de relações podem ser observados entre os indivíduos participantes. Nas relações competitivas, a distribuição de reforços depende do desempenho relativo dos participantes de modo que os reforços obtidos por um participante são, pelo menos em parte, dependentes do comportamento de outro indivíduo (Hake \& Vukelich, 1972; Schmitt, 1984,

1 Esse estudo foi realizado com o apoio do PIBIC/CNPq. Agradecemos a colaboração de Alessandra da Silva Souza, Letícia de Faria Santos e Isa Albuquerque Barbosa na coleta e análise de dados. Dados parciais desse trabalho foram apresentados na XXX Reunião Anual de Psicologia da Sociedade Brasileira de Psicologia, Brasília.

2 Endereço: Universidade de Brasília - Instituto de Psicologia - Depto. de Processos Psicológicos Básicos, 70.910-900 - Brasília-DF. E-mail: abreu@unb.br
1987, 1998). Nas relações individuais, por outro lado, os reforços são obtidos quando um critério de desempenho individual é atingido, não havendo, portanto, interdependência de reforços (Schmitt, 1998).

O comportamento social tem sido freqüentemente analisado por meio de procedimentos de escolha entre uma tarefa competitiva e uma tarefa individual. Em geral, os estudos têm sugerido que a escolha entre essas duas alternativas é influenciada pela iniqüidade de reforços e pela instrução fornecida aos participantes (Buskist, Barry, Morgan \& Rossi, 1984; Dougherty \& Cherek, 1994; Matthews, 1979; Schmitt, 1987, 1998).

Os efeitos da iniqüidade entre os reforços obtidos pelos participantes de uma tarefa competitiva foram investigados por Schmitt (1987, Experimento 3). Nesse estudo, os reforços eram liberados de acordo com um esquema de intervalo variável (VI). Na alternativa individual, as respostas de ambos os participantes produziam o reforço (VI não-competitivo); já na alternativa de competição, apenas o participante que primeiro respondesse após a passagem do intervalo re- 
cebia o reforço (VI competitivo), cuja magnitude era três vezes maior do que na alternativa individual. Os dados indicaram que quanto maior o número de perdas na contingência competitiva (o que produzia iniqüidade desfavorável ao participante que estava perdendo), maior a preferência pela contingência individual (ver também Schmitt, 1998).

A escolha entre tarefas competitivas e individuais também é afetada pela presença de instruções. Instruções ${ }^{3}$ são estímulos verbais antecedentes que descrevem, completa ou parcialmente, os termos de uma contingência de reforço, ou seja, descrevem uma relação funcional entre um antecedente, uma resposta e sua consequiência (Baum, 1994/1999; Cerutti, 1989; Skinner, 1969). A literatura sobre controle verbal tem demonstrado dois efeitos sistemáticos do uso de instruções: (a) a aquisição do responder é facilitada (Ayllon \& Azrin, 1964; Danforth, Chase, Dolan \& Joyce, 1990; Dermer \& Rodgers, 1997; Galizio, 1979; Rosenfarb, Newland, Brannon \& Howey, 1992) e (b) a sensibilidade desse responder a mudanças nas contingências é reduzida (Dixon \& Hayes, 1998; Kaufman, Baron \& Kopp, 1966; Okouchi, 1999; Otto, Torgrud \& Holborn, 1999; Wulfert, Greenway, Farkas, Hayes \& Dougher, 1994). O termo sensibilidade comportamental refere-se àquelas situações em que mudanças nas contingências são seguidas por mudanças no comportamento; o termo insensibilidade, por outro lado, é empregado quando mudanças nas contingências são acompanhadas pela persistência de padrões comportamentais anteriormente reforçados (Madden, Chase \& Joyce, 1997).

Estudos sobre competição também têm indicado que instruções afetam a aquisição e sensibilidade do comportamento. Buskist e cols. (1984), por exemplo, observaram a influência de instruções sobre a aquisição. Os participantes, divididos em duplas, foram expostos a um esquema FI não-competitivo e, em seguida, a um esquema FI competitivo no qual apenas o participante que completasse a tarefa em primeiro lugar receberia o reforço. Foi observado que a implementação da contingência de competição produziu um aumento na taxa de respostas de todos os participantes, promovendo um responder mais eficiente, mas esse aumento ocorreu mais rapidamente para aqueles participantes que receberam instruções sobre competição.

Dougherty e Cherek (1994) ofereceram evidências do efeito de instruções sobre a sensibilidade comportamental em situações de competição. Os participantes que receberam instruções indicando que poderiam escolher entre competir com um parceiro ou trabalhar sozinho mostraram uma preferência acentuada pela alternativa de competição, mesmo quando a probabilidade do reforço era maior na alternativa individual. Para aqueles participantes que não receberam essas instruções, o comportamento de escolha variou como uma função direta da probabilidade relativa do reforço. Esses resultados sugerem que instruções sobre a contingência de competição e sobre a presença de outra pessoa

1 Instruções e regras serão aqui tratados como termos funcionalmente equivalentes. diminuem a sensibilidade do comportamento de escolha a manipulações na probabilidade do reforço.

Os efeitos de instruções sobre a sensibilidade do comportamento de escolha às manipulações na iniqüidade de reforços foram investigados por Matthews (1979). Na alternativa individual, a magnitude do reforço era idêntica para ambos os participantes de cada dupla. Na alternativa de competição, entretanto, a magnitude do reforço foi manipulada ao longo das condições experimentais, de modo que havia condições em que os Participantes 1 e 2 recebiam o mesmo número de reforços (eqüidade), outras em que o Participante 2 recebia duas vezes mais reforços que o Participante 1 (baixa iniqüidade) e, finalmente, condições em que o Participante 2 recebia quatro vezes mais reforços que o outro (alta iniqüidade). A alternativa de competição entrava em vigor apenas se ambos os participantes a escolhessem; se um ou ambos os participantes escolhessem a alternativa individual, esta entrava em vigor. Além disso, os participantes receberam instruções precisas sobre a distribuição dos reforços em cada condição. No Experimento 1 foi observada uma relação inversa entre escolha por competição e iniqüidade (desfavorável) de reforços, corroborando os dados obtidos por Schmitt $(1987,1998)$.

O Experimento 2 incluiu uma fase adicional em que ocorria uma reversão na iniqüidade de reforços entre os participantes: na primeira fase, idêntica ao Experimento 1, o Participante 2 sempre ganhava mais reforços nas condições de iniqüidade enquanto, na segunda fase, o Participante 1 passava a ganhar mais reforços nessas condições. Antes da reversão, a escolha por competição foi mais acentuada que aquela observada no Experimento 1, mesmo para os participantes que estavam em desvantagem de reforços, sugerindo insensibilidade do comportamento de escolha à iniqüidade desfavorável de reforços. Após a reversão, entretanto, os participantes que passaram a receber menos reforços diminuíram suas escolhas por competição, apontando sensibilidade à iniqüidade desfavorável. Provavelmente isto ocorreu porque as instruções indicavam que não ocorreriam reversões adicionais e, portanto, a única possibilidade de diminuir a iniqüidade desfavorável era escolhendo a alternativa individual.

Uma vez que a literatura sobre controle verbal tem indicado que o grau de precisão das instruções afeta a sensibilidade comportamental às mudanças ambientais (Danforth $\mathrm{e}$ cols., 1990; DeGrandpre \& Buskist, 1991; Newman, Buffington \& Hemmes, 1995), é possível sugerir que os resultados obtidos por Matthews (1979) foram produzidos, pelo menos em parte, pela precisão das instruções. Ou seja, as diferenças na sensibilidade do comportamento de escolha ao longo das condições, caracterizadas por aumentos e diminuições na escolha por competição antes e após a reversão, respectivamente, podem ter sido produzidas pela informação de como e quando a reversão ocorreria. Além disso, no estudo de Matthews, as instruções e a iniqüidade de reforços foram manipuladas simultaneamente, não sendo possível avaliar a contribuição isolada de cada uma dessas variáveis para o comportamento de escolha. 
Dessa forma, o objetivo do presente estudo consistiu em investigar se o controle exercido pela iniqüidade de reforços sobre a escolha entre uma tarefa competitiva e uma tarefa individual seria afetado pelo grau de precisão das instruções. Mais especificamente, foi investigado se a diminuição na escolha por competição após a reversão na iniqüidade de reforços, observada no estudo de Matthews (1979), seria minimizada, ou mesmo eliminada, na presença de instruções imprecisas e/ou na ausência de instruções. Os participantes foram divididos em três grupos: sem instrução, com instrução precisa e com instrução imprecisa. O primeiro grupo não recebeu qualquer instrução sobre a reversão na iniqüidade de reforços. Para o segundo grupo, as instruções foram semelhantes àquelas utilizadas por Matthews. As instruções do terceiro grupo informavam sobre a ocorrência de reversão, ou seja, que em alguns momentos os participantes estariam recebendo mais reforços que seus parceiros e que, em outros momentos, o inverso ocorreria, mas não informavam como, quando ou quantas reversões ocorreriam.

\section{Método}

\section{Participantes}

Sessenta e dois estudantes universitários, do curso de Psicologia da Universidade de Brasília, participaram do experimento. Apenas trinta participantes (quinze duplas) atingiram os critérios para a mudança de condições e, assim, finalizaram o experimento. Todos os participantes receberam pontos em disciplinas correspondentes a cada hora de participação no experimento ( 0,5 ponto/hora). Além disso, os participantes que finalizaram o experimento participaram de um sorteio de $\mathrm{R} \$ 50,00$.

\section{Ambiente/Material}

O experimento foi conduzido em uma sala $(6 \times 6 \mathrm{~m})$ que continha uma mesa, três cadeiras (uma para um dos experimentadores e duas para os participantes) e uma divisória de madeira situada sobre a mesa. Havia um quadro negro, perpendicular à mesa, onde eram registrados os pontos ganhos por cada participante em cada tentativa, bem como o total de pontos de cada um, de forma que os participantes poderiam continuamente ver seus pontos e os de seus parceiros. Em frente a cada participante havia duas fichas $(5 \mathrm{x}$ $30 \mathrm{~cm}$ ), uma azul e uma branca, uma cartolina com as instruções sobre o experimento e, também, canetas e folhas em branco onde cada participante deveria registrar os pontos por ele ganhos.

\section{Procedimento}

Foram utilizadas diversas estratégias para impedir que os participantes viessem a conhecer a identidade de seus parceiros. Primeiro, para cada participante da dupla foi combinado um local diferente de encontro com o experimentador; segundo, os participantes de cada dupla foram encaminhados separadamente à sala de coleta de dados; e, terceiro, a divisória de madeira sobre a mesa impedia o contato visual entre os participantes que se sentavam em lados opostos da mesa. Os participantes de cada dupla foram nomeados aleatoriamente como Participante 1 e Participante 2.

No início da sessão, o Experimentador 1 lia as instruções, as quais eram repetidas caso um ou ambos os sujeitos apresentassem dúvidas sobre a tarefa de escolha. Em seguida, esse experimentador sinalizava o início da tentativa. Após os participantes efetuarem suas escolhas, o Experimentador 2 registrava, no quadro-negro, os pontos ganhos em cada tentativa e os pontos acumulados ao longo das tentativas, por cada um dos participantes. Esses pontos ficavam disponíveis no quadro negro durante toda a sessão. Era solicitado aos participantes que registrassem os pontos ganhos na tentativa em uma folha de papel. O início de uma nova tentativa era, então, sinalizada. Após a nona tentativa, o Experimentador 1 sinalizava o final da sessão.

O presente estudo compreendeu quatro fases experimentais (Individual 1, Individual 8, Ponto de Mudança e Teste), programadas de modo semelhante aquele descrito no Experimento 2 de Matthews (1979), conforme explicitado a seguir. No início da primeira fase era fornecida aos participantes a seguinte instrução:

Este é um experimento sobre aprendizagem.

Você estará trabalhando com um parceiro e ambos terão uma tarefa idêntica para executar durante o experimento.

Você e seu parceiro receberão, cada um, duas fichas (uma azul e outra

branca). Quando o experimentador disser a palavra "ATENÇÃO", você terá três opções de escolha:

(1) colocar a mão sobre a ficha azul;

(2) colocar a mão sobre a ficha branca; $e$

(3) colocar a mão sobre a mesa.

Após sua escolha, o experimentador dirá a palavra "AGO$R A$ ”. Se você tiver escolhido uma das fichas, coloque a mesma na abertura da divisória; caso contrário, basta estender seu braço em direção à abertura da divisória. Desse modo, você e seu parceiro tomarão conhecimento das escolhas de cada um ao longo do experimento.

A cada tentativa, você receberá um determinado número de pontos que dependerá da sua escolha e da escolha de seu parceiro. Os pontos ganhos serão trocados por fichas ao final da sessão. Essas fichas lhe darão direito a participar de um sorteio em dinheiro ao final do experimento. Assim, quanto mais pontos você ganhar, mais fichas receberá e, portanto, maiores serão suas chances de ganhar o sorteio.

Os experimentadores lhe avisarão quando essa sessão terminar.

Por favor, permaneça sentado e NÃO CONVERSE com o seu parceiro ou com os experimentadores durante a sessão. É extremamente importante que você e seu parceiro não conheçam a identidade um do outro.

Todas as informações necessárias para participar do experimento estão contidas nessa Folha de Instruções. Em caso de 
dúvida, releia as instruções (não faça perguntas aos experimentadores).

Quando estiver pronto (a) para começar, levante sua mão direita.

Fase 1 (Individual 1). Quando a alternativa individual era escolhida, isto é, quando pelo menos um participante não colocava uma das fichas na abertura da divisória (apenas estendia o braço), cada participante recebia um ponto. Quando ambos os participantes colocavam fichas sob a divisória, a alternativa de competição entrava em vigor: se as fichas fossem de cores diferentes, o Participante 1 ganhava dois pontos e o Participante 2 ganhava cinco pontos; se as fichas fossem de cores iguais, o Participante 1 ganhava cinco pontos e o Participante 2 ganhava dois pontos.

O objetivo dessa fase consistiu em verificar se o comportamento de escolha dos participantes era sensível à magnitude do reforço. Caso sim, deveria ser observada uma maior preferência pela alternativa competitiva, pois esta oferecia um maior número de pontos que a alternativa individual.

Ao final da sessão (nove tentativas), os experimentadores calculavam a proporção de escolhas por competição para a dupla. Caso essa proporção fosse maior ou igual a 6/9, passava-se à Fase 2. Caso a proporção fosse inferior a 6/9, repetia-se a sessão. Se, ao final dessa repetição, a proporção fosse superior a 6/9, passava-se à segunda fase; caso contrário, os participantes eram eliminados do estudo.

Fase 2 (Individual 8). O procedimento, bem como o objetivo, dessa fase era semelhante aquele descrito na Fase 1, com a seguinte diferença: quando um ou ambos os participantes escolhiam a alternativa individual, cada participante ganhava oito pontos na tentativa. Dessa forma, se o comportamento de escolha fosse sensível à magnitude do reforço, uma menor preferência pela alternativa de competição seria obtida, já que esta alternativa oferecia menos pontos que a alternativa individual.

Se, ao final de nove tentativas, a proporção de escolhas por competição resultasse em um valor menor ou igual a 3/ 9, passava-se para a Fase 3. Caso essa proporção ficasse acima de $3 / 9$, repetia-se a sessão. Se, após a segunda sessão, a proporção continuasse maior que $3 / 9$, a participação da dupla era cancelada; caso contrário, iniciava-se a terceira fase.

Fase 3 (Ponto de Mudança). O objetivo dessa fase era determinar a distribuição de pontos entre alternativas necessárias para produzir mudança na preferência dos participantes, o que foi feito por meio de manipulações no número de pontos programados para a alternativa individual. Ou seja, quando o número de pontos na alternativa individual era igual a um, os participantes apresentavam preferência pela alternativa competitiva (ver Fase 1). A questão, então, era identificar o número de pontos que deveria ser liberado na alternativa individual de modo que os participantes passassem a preferir essa alternativa. O número de pontos na alternativa individual imediatamente anterior à mudança na preferência foi denominado de ponto de mudança.

Dessa forma, esperava-se identificar uma distribuição de pontos que gerasse uma distribuição de escolhas aproximadamente eqüitativa entre as duas alternativas. Uma distri- buição eqüitativa não era possível porque a sessão compreendia nove tentativas e, assim, a dupla apresentava um número maior de escolhas ou pela alternativa de competição ou pela alternativa individual. Uma vez que a literatura indica que aumentos na iniqüidade desfavorável de reforços tendem a gerar respostas de fuga e esquiva de competição, optou-se por iniciar o experimento com a distribuição de pontos que tivesse gerado um número maior de escolhas por competição.

Essa fase foi iniciada com dois pontos programados para a alternativa individual. Se, após nove tentativas, a proporção de escolhas por competição indicasse mudança na preferência, ou seja, que os participantes passaram a escolher a alternativa individual, o ponto de mudança para a dupla seria igual a um. Se, ao contrário, os participantes continuassem preferindo a alternativa competitiva, aumentava-se o número de pontos na alternativa individual para três, e assim por diante. Quando o ponto de mudança era estabelecido, iniciava-se a Fase 4.

Fase 4 (Teste). Na alternativa individual, o número de pontos ganhos por cada participante da dupla era igual ao ponto de mudança daquela dupla e permanecia constante ao longo dessa fase. Na alternativa competitiva, o número de pontos foi manipulado ao longo de cinco condições experimentais: equiidade (1:1), onde os participantes ganhavam o mesmo número de pontos; baixa iniquiidade (1:2), onde o Participante 2 ganhava duas vezes mais que o Participante 1; alta iniqüidade (1:4), onde o Participante 2 ganhava quatro vezes mais que o Participante 1 ; baixa iniqüidade (2:1), onde o Participante 1 ganhava duas vezes mais que o Participante 2; e alta iniqüidade (4:1), onde o Participante 1 ganhava quatro vezes mais que o Participante 2.

A Tabela 1 apresenta a distribuição programada de pontos na alternativa individual e na alternativa de competição em cada condição experimental. Na alternativa individual, o

Tabela 1. Distribuição programada de pontos em cada alternativa. Para a alternativa individual são apresentados os valores médios de cada grupo.

\begin{tabular}{llcr}
\hline \multicolumn{1}{c}{ Alternativa } & \multicolumn{2}{c}{ Participantes } \\
\cline { 2 - 3 } Individual (todas as condições) & $\mathbf{1}$ & $\mathbf{2}$ \\
Grupo sem instrução & 3,2 & 3,2 \\
Grupo inst. precisa & & 3,4 & 3,4 \\
Grupo inst. imprecisa & & 3,2 & 3,2 \\
\hline Competição (todos os grupos) & & \\
Condição 1:1 & cores iguais & 5 & 2 \\
& cores diferentes & 2 & 5 \\
Condição 1:2 & cores iguais & 5 & 4 \\
Condição 2:1 & cores diferentes & 2 & 10 \\
& cores iguais & 4 & 5 \\
Condição 1:4 & cores diferentes & 10 & 2 \\
& cores iguais & 5 & 8 \\
Condição 4:1 & cores diferentes & 2 & 20 \\
& cores iguais & 8 & 5 \\
& cores diferentes & 20 & 2 \\
\hline
\end{tabular}


ponto de mudança indicado para cada grupo corresponde à média dos pontos de mudanças obtidos para os Participantes 1 (e para os Participantes 2) do grupo em questão. Na alternativa competitiva, as proporções indicadas para cada condição correspondem à média dos pontos programados nos dois tipos de tentativas (cores iguais e cores diferentes) para cada participante. Dessa forma, considerando apenas os valores médios, na Condição 1:1, tanto o Participante 1 quanto o Participante 2 poderia ganhar 3,5 pontos; na condição 1:2, o Participante 1 poderia ganhar 3,5 pontos, enquanto o Participante 2 poderia ganhar 7 pontos (o inverso ocorria na proporção 2:1); e na Condição 1:4, o Participante 1 poderia ganhar 3,5 pontos e o Participante 4 passava a ganhar 14 pontos (o inverso ocorria na Condição 4:1).

É importante ressaltar que, para aqueles participantes com ponto de mudança igual ou menor do que três, a escolha da alternativa competitiva produziria um maior número de pontos que a escolha da alternativa individual, em todas as condições programadas. Por outro lado, no caso de iniqüidade desfavorável (e.g., Participante 1 nas Condições 1:2 e 1:4), a escolha da alternativa individual poderia gerar diminuição nessa iniqüidade.

A ordem de apresentação das condições seguia três critérios: primeiro, as condições de iniquiidade foram sempre intercaladas com a condição de eqüidade; segundo, cada condição de iniqüidade era apresentada duas vezes; e, terceiro, as condições de iniqüidade em que o Participante 2 ganhava mais pontos que o Participante 1 foram apresentadas antes daquelas em que o inverso ocorria. Dessa forma, os participantes foram expostos às condições 1:1, 1:2, 1:1, $1: 4,1: 1,1: 4,1: 1$ e $1: 2$ antes da reversão e às condições $1: 1$, 2:1, 1:1, 4:1, 1:1, 4:1, 1:1 e 2:1 após a reversão. Cada condição estava em vigor durante uma sessão de seis tentativas.

Nessa fase, as duplas de participantes foram aleatoriamente separadas em três grupos: sem instrução, instrução precisa e instrução imprecisa. A instrução apresentada para as duplas do grupo sem instrução era idêntica àquela da Fase 1. Para as duplas dos demais grupos foram acrescentadas instruções adicionais após a frase "A cada tentativa, você receberá um determinado número de pontos que dependerá da sua escolha e da escolha de seu parceiro". Para o grupo com instrução precisa foi acrescentado:

Durante algumas tentativas você ganhará mais pontos do que o seu parceiro; em outras tentativas ocorrerá o contrário, ou seja, seu parceiro ganhará mais pontos do que você; e, finalmente, em algumas tentativas vocês ganharão o mesmo número de pontos. O experimentador lhe dará uma folha com informações sobre a distribuição de pontos para cada bloco de seis tentativas.

No caso do grupo com instrução imprecisa , foi adicionado:

Durante algumas tentativas você ganhará mais pontos do que o seu parceiro; em outras tentativas ocorrerá o contrário, ou seja, seu parceiro ganhará mais pontos do que você; e, final- mente, em algumas tentativas vocês ganharão o mesmo número de pontos.

Para os participantes do grupo com instrução precisa foi também fornecida uma folha que indicava todas as condições do experimento, como no estudo de Matthews (1979), com suas respectivas distribuições de pontos, bem como a ordem de apresentação dessas condições.

Ao final da leitura das instruções, todos os participantes eram instruídos a registrar, em uma folha de papel, o número de pontos ganhos por ele a cada tentativa. As Fases 1, 2 e 3 foram realizadas em um mesmo dia, enquanto a Fase 4 foi realizada em um dia subseqüente. Os participantes foram informados que sua participação no experimento duraria de um a cinco dias, a fim de evitar que as escolhas dos participantes fossem influenciadas pelo conhecimento de quantas reversões ocorreriam durante o experimento.

\section{Resultados}

A sensibilidade do comportamento de escolha de cada grupo foi avaliada por meio da porcentagem média de escolhas pela alternativa de competição. Essa medida foi obtida dividindo-se, inicialmente, o número de escolhas por competição de cada participante, em cada condição, pelo número total de tentativas na condição correspondente, sendo o quociente multiplicado por 100. Em seguida, as porcentagens de escolha por competição de todos os participantes que estavam em desvantagem de pontos (perdedores), em cada condição, foram somadas e divididas pelo número desses participantes (sempre cinco). $\mathrm{O}$ mesmo foi feito para obter as porcentagens médias dos participantes em vantagem de pontos (ganhadores) em cada condição. Valores acima de $50 \%$ indicam preferência por competição, valores abaixo de $50 \%$ indicam preferência pela alternativa individual e valores iguais a $50 \%$ indicam ausência de preferência.

A Figura 1 apresenta a porcentagem média de escolha por competição para todos os grupos, em cada condição, antes e após a reversão na iniqüidade de reforços. As linhas verticais mostram o desvio padrão. Para cada condição, as barras pretas indicam os dados dos ganhadores e as barras brancas, dos perdedores. Além disso, a barra da esquerda mostra os resultados do Participante 1 de cada dupla enquanto a barra da direita, os resultados do Participante 2. A notação de cada condição indica a razão programada de pontos: o número à esquerda refere-se ao Participante 1 e o número à direita, ao Participante 2.

Para o grupo SEM INSTRUÇÃO foram observados os seguintes resultados. Primeiro, ganhadores e perdedores mostraram porcentagens diferenciadas de escolha por competição. Segundo, antes da ocorrência da reversão, os participantes que estavam perdendo (Participantes 1) apresentaram uma diminuição na escolha por competição em função do aumento na iniquiidade desfavorável de reforços e os participantes que estavam ganhando (Participantes 2) escolheram quase exclusivamente a alternativa de competição em todas as condições. Dessa forma, enquanto as porcentagens de escolha dos perdedores variou de $61 \%$ (na primeira con- 


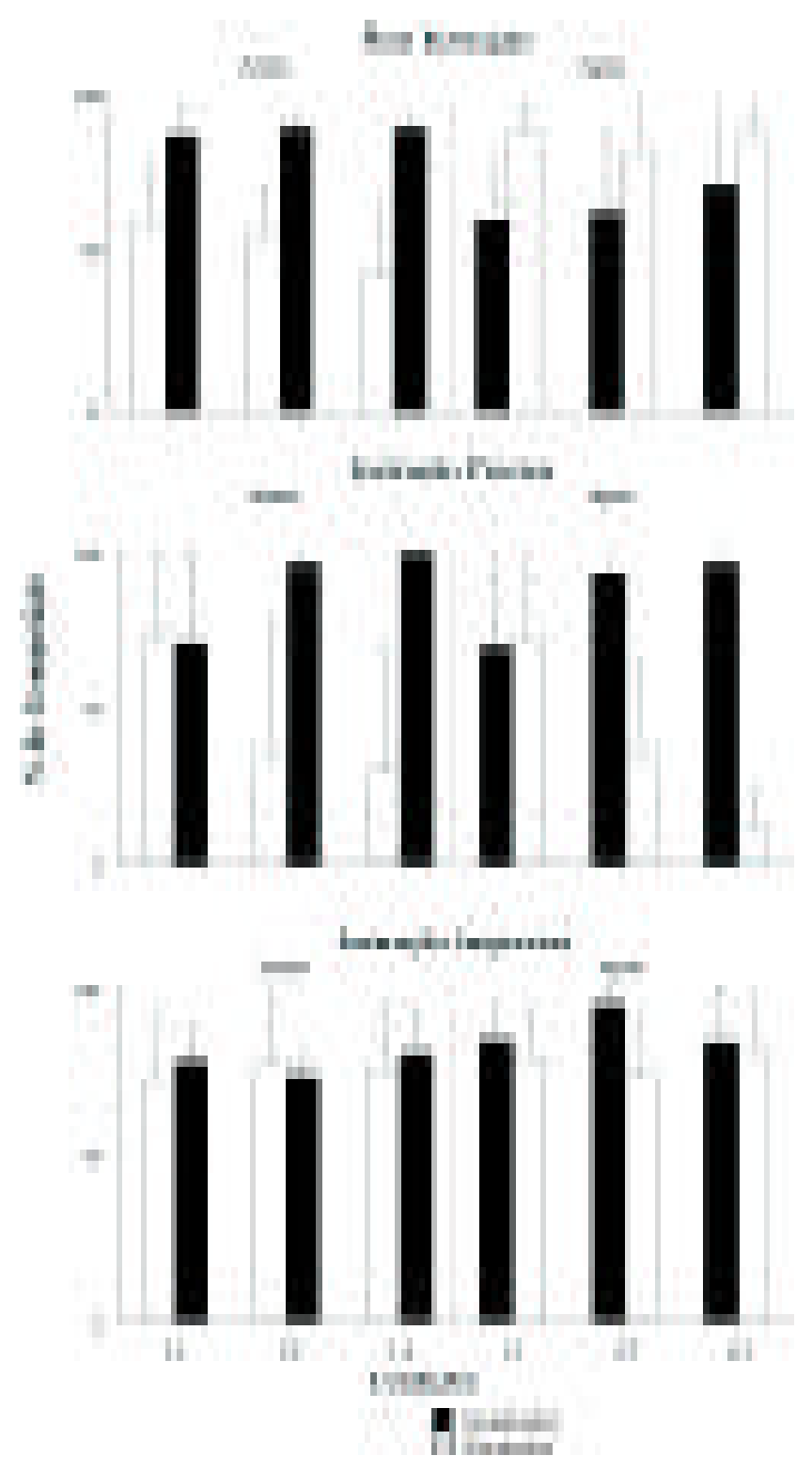

Figura 1. Porcentagem média de escolhas pela alternativa de competição, em cada condição experimental, antes e após a reversão. Em cada condição, a barra da esquerda corresponde ao Participante 1 e a barra da direita, ao Participante 2 .

dição) para $43 \%$ (na terceira condição), as porcentagens de escolha dos ganhadores manteve-se aproximadamente igual a 90\%. Após a reversão, os participantes que estavam perdendo (Participantes 2) mostraram valores percentuais altos (entre 83 e $89 \%$ ), mesmo na condição 4:1, indicando manutenção da preferência por competição observada antes da reversão. Os participantes que estavam ganhando (Participantes 1) apresentaram porcentagens semelhantes de escolha por competição nas condições 1:1 e 2:1 (61\% e 63\%, respectivamente) mas, com o aumento na iniquiidade desfavorável, foi observado um aumento na escolha por competição (72\%). A análise de variância, que comparou as porcentagens médias de escolha em todas as condições, mostrou haver uma diferença estatisticamente significativa entre as

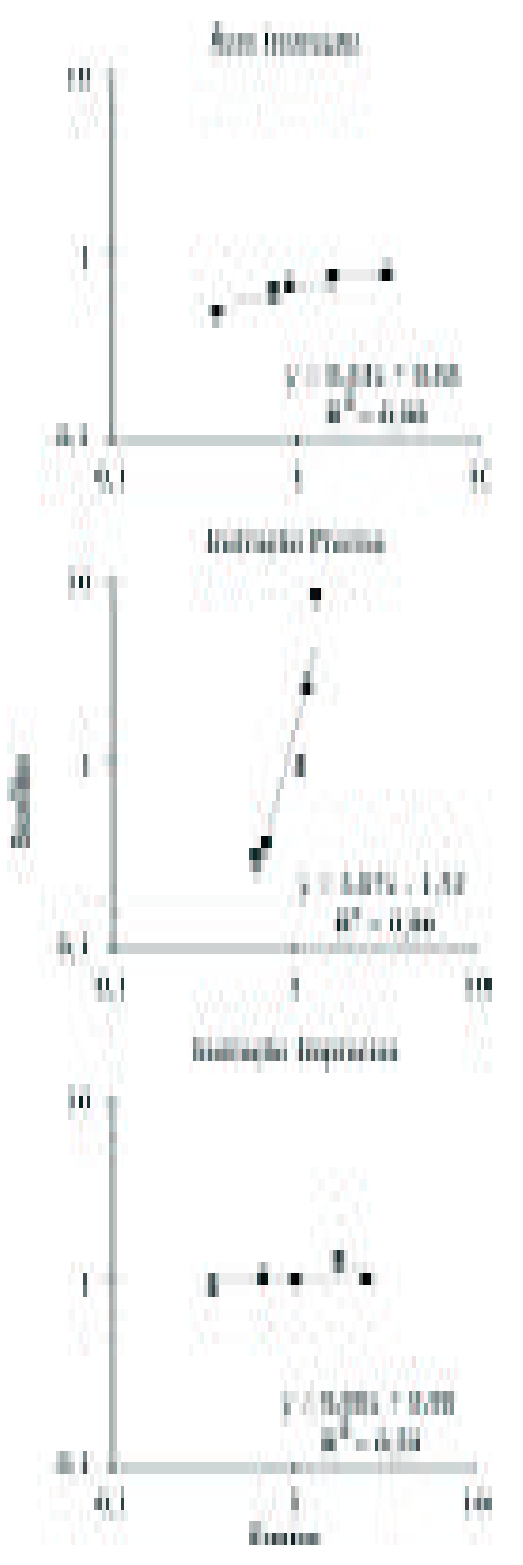

Figura 2. Logaritmo das razões de escolha por competição em função do logaritmo das razões de pontos obtidos na alternativa de competição. Para cada grupo, os valores mostrados correspondem às cinco manipulações efetuadas na razão de pontos (o valor da condição 1:1 representa a média dos pontos obtidos nas duas ocorrências dessa condição). A reta de regressão, a equação da reta e o valor de $\mathrm{R}^{2}$ são também apresentados.

médias dos ganhadores e perdedores $[\mathrm{F}(11,48)=4,824 ; \mathrm{p}=$ $0,000]$. O teste Tukey indicou que essa diferença ocorreu na condição 1:4. As demais comparações - ganhador (ou perdedor) ao longo das condições, antes e após a reversão não revelaram diferenças estatisticamente significativas.

No grupo com INSTRUÇÃO PRECISA, a escolha pela alternativa competitiva foi controlada pela iniqüidade de reforços no decorrer das condições. Os dados indicam que os ganhadores preferiram a alternativa competitiva em todas as condições enquanto os perdedores preferiram a alternativa individual nas condições de baixa e alta iniqüidade. Com os aumentos na iniqüidade, a escolha por competição aumentou para os ganhadores e diminuiu para os perdedores, tanto antes quanto após a reversão. Os valores percentuais obser- 
vados para os ganhadores antes da reversão (entre 71 e 100\%) são semelhantes àqueles obtidos pelos ganhadores após a reversão (70 e 97\%), o mesmo ocorrendo em relação aos perdedores (entre 30 e $71 \%$, antes da reversão e entre 12 e $73 \%$, após a reversão). $\mathrm{O}$ teste $\mathrm{F}$ apontou diferenças estatisticamente significativas $[\mathrm{F}(11,48)=5,546 ; p=0,000]$. $\mathrm{O}$ teste Tukey mostrou que essa diferença ocorreu entre ganhador e perdedor nas condições de iniqüidade (1:2 1:4, 2:1 e 4:1). As demais diferenças - ganhador (perdedor) ao longo das condições e ganhador (perdedor) antes e após a reversão em cada condição - não foram estatisticamente significativas.

Para o grupo com INSTRUÇÃO IMPRECISA, o percentual de escolha por competição foi similar entre os participantes da dupla em todas as condições. Ganhadores e perdedores apresentaram porcentagens de escolha por competição iguais ou maiores que 73, indicando preferência pela alternativa de competição a despeito das manipulações na iniqüidade de reforços, tanto antes quanto após a reversão. $\mathrm{O}$ teste $\mathrm{F}$ realizado, semelhante àqueles dos outros dois grupos, não indicou diferenças estatisticamente significativas.

A Figura 2 apresenta o logaritmo das razões de escolha por competição em função do logaritmo das razões de pontos obtidos na alternativa de competição para cada grupo. Os valores mostrados indicam as cinco manipulações efetuadas na razão de pontos, sendo o valor da condição $1: 1$ correspondente à média dos pontos obtidos nas duas ocorrências dessa condição. A reta de regressão e a equação da reta são também apresentadas. Nessa equação $(\mathrm{y}=\mathrm{ax}+\mathrm{b}), b$ representa a interseção da reta e $a$, a inclinação. A inclinação indica se mudanças no eixo $\mathrm{x}$ foram acompanhadas por mudanças proporcionalmente similares $(\mathrm{a}=1,0)$, menores $(\mathrm{a}<1,0)$ ou maiores $(\mathrm{a}>1,0)$ no eixo y. Isto é, o valor de $a$ é um índice da sensibilidade do comportamento de escolha às manipulações na distribuição de pontos entre os participantes. Os valores de $\mathrm{R}^{2}$ consistem em uma estimativa do quanto da variação na escolha poderia ser explicada a partir da variação nos pontos.

Os valores da inclinação da reta mostram que as mudanças na escolha por competição foram proporcionalmente menores (grupos sem instrução e com instrução imprecisa) ou maiores (grupo com instrução precisa) que as mudanças nos pontos obtidos. Mais especificamente, dentre os três grupos, a sensibilidade do comportamento de escolha foi menor para o grupo com instrução imprecisa, maior para o grupo com instrução precisa e intermediária para o grupo sem instrução. Os valores de $\mathrm{R}^{2}$ indicam que as mudanças na razão de escolha por competição, observadas para grupos sem instrução e com instrução precisa, podem ser atribuídas às mudanças na razão de pontos.

A Tabela 2 mostra o número médio de pontos obtidos pelos Participantes 1 e 2, em cada condição e ao final do experimento, e por cada grupo. Para os três grupos, os Participantes 1 e 2 ganharam um número de pontos aproximadamente igual nas condições 1:1 (com exceção da primeira condição 1:1 do grupo sem instrução); nas condições de iniqüidade, por outro lado, o número de pontos obtidos foi maior para o ganhador (Participante 2, antes da reversão; Participante 1, após a reversão) do que para o perdedor (Participantes 1 e 2, antes e após a reversão, respectivamente), principalmente nos grupos sem instrução e com instrução imprecisa. Embora a iniquiidade entre os pontos obtidos pelos Participantes 1 e 2 não tenha correspondido à iniqüidade programada (na condição 1:2, por exemplo, os Participantes 2 não obtiveram exatamente o dobro do número de pontos ganhos pelos Participantes 1), a proporção de pontos obtidos aumentou diretamente com a proporção de pontos programada, tanto antes quanto após a reversão. A análise de variância, que comparou o número médio de pontos em todas as condições, apontou diferenças estatisticamente significativas apenas para os grupos sem instrução e com instrução imprecisa $[\mathrm{F}(11,48)=12,123 ; \mathrm{p}=0,00$ e $\mathrm{F}(11,48)=$ 11,$658 ; \mathrm{p}=0,00$, respectivamente). O teste Tukey indicou que essas diferenças ocorreram entre: (a) ganhador e perdedor nas condições 1:4 e 4:1 dos dois grupos; (b) condições 1:2 e 1:4 do ganhador nos dois grupos; (c) condições 1:1 e 4:1 e condições $2: 1$ e 4:1 do ganhador no grupo sem instrução, condições 2:1 e 4:1 do ganhador no grupo com instrução imprecisa; (d) condições 1:1 e 1:4 do perdedor no grupo sem instrução, condições 1:1 e 1:2 e condições 1:1 e 1:4 do

Tabela 2. Pontos médios obtidos pelos participantes 1 e 2 (P1 e P2, respectivamente), em cada condição e ao final do experimento, e por cada um dos três grupos.

\begin{tabular}{|c|c|c|c|c|c|c|c|c|c|}
\hline \multirow{2}{*}{$\begin{array}{c}\text { Grupos } \\
\text { Participantes }\end{array}$} & & \multicolumn{3}{|c|}{ Antes } & \multicolumn{3}{|c|}{ Após } & \multirow{2}{*}{ Total } & \multirow{2}{*}{$\begin{array}{l}\text { Total } \\
\text { Grupo }\end{array}$} \\
\hline & & $1: 1$ & $1: 2$ & $1: 4$ & $1: 1$ & $2: 1$ & $4: 1$ & & \\
\hline \multirow[t]{4}{*}{ Sem Instrução } & P1 & 73,2 & 41,4 & 35,2 & 77,8 & 65,0 & 126,6 & 69,9 & 67,9 \\
\hline & & $(16,4)$ & $(8,6)$ & $(9,8)$ & $(10,5)$ & $(12,3)$ & $(36,7)$ & $(34,6)$ & $(14,8)$ \\
\hline & $\mathrm{P} 2$ & 83,4 & 55,0 & 95,0 & 80,4 & 41,2 & 40,8 & 66,0 & \\
\hline & & $(13,2)$ & $(13,3)$ & $(29,0)$ & $(17,1)$ & $(7,4)$ & $(5,2)$ & $(26,3)$ & \\
\hline \multirow[t]{4}{*}{ Inst. Precisa } & P1 & 86,6 & 42,6 & 45,2 & 90,4 & 51,2 & 54,2 & 61,7 & 63,5 \\
\hline & & $(24,6)$ & $(12,9)$ & $(13,7)$ & $(18,1)$ & $(18,2)$ & $(24,8)$ & $(26,4)$ & $(9,0)$ \\
\hline & $\mathrm{P} 2$ & 87,8 & 60,0 & 74,0 & 85,0 & 44,2 & 41,0 & 65,3 & \\
\hline & & $(23,5)$ & $(22,0)$ & $(37,7)$ & $(22,7)$ & $(12,1)$ & $(13,1)$ & $(28,4)$ & \\
\hline \multirow[t]{4}{*}{ Inst. Imprecisa } & P1 & 81,6 & 42,2 & 40,8 & 84,6 & 71,8 & 110,6 & 71,9 & 71,0 \\
\hline & & $(18,2)$ & $(8,1)$ & $(11,2)$ & $(17,1)$ & $(14,2)$ & $(25,7)$ & $(29,2)$ & $(14,0)$ \\
\hline & $\mathrm{P} 2$ & 79,8 & 62,4 & 111,8 & 82,6 & 40,6 & 43,2 & 70,1 & \\
\hline & & $(19,8)$ & $(12,5)$ & $(28,7)$ & $(11,1)$ & $(7,2)$ & $(12,8)$ & $(29,4)$ & \\
\hline
\end{tabular}


perdedor no grupo com instrução imprecisa; (e) condições 1:1 e 2:1 e condições 1:1 e 4:1 do perdedor nos dois grupos.

Nos três grupos, os Participantes 1 e 2 ganharam aproximadamente o mesmo número médio de pontos ao final do experimento, um resultado que foi confirmado pela análise de variância, a qual não revelou diferenças estatisticamente significativas entre essas médias. Finalmente, dentre os três grupos, o grupo instrução imprecisa ganhou o maior número de pontos e o grupo instrução precisa ganhou o menor número de pontos, mas as diferenças entre os grupos não foram estatisticamente significativas.

\section{Discussão}

As manipulações no grau de precisão da instrução afetaram diferencialmente o controle exercido pela iniqüidade de reforços sobre a escolha entre as alternativas competitiva e individual. Com a instrução precisa, a escolha por competição de ambos participantes variou sistematicamente com as manipulações na iniqüidade de reforços; com a instrução imprecisa, ambos participantes escolheram predominantemente a alternativa de competição ao longo das condições; $\mathrm{e}$ na ausência de instruções sobre reversão, foi observada tanto uma relação inversa entre escolha por competição e iniqüidade desfavorável (para o participante que iniciou o experimento com desvantagem de pontos), quanto escolha quase exclusiva por competição (para o participante que começou com vantagem de pontos). Esses resultados indicam que não houve redução na escolha por competição após a reversão, para os grupos sem instrução e com instrução imprecisa, sugerindo que a diminuição na proporção de escolhas por competição, relatada por Matthews (1979), foi produzida pelo uso de instruções precisas sobre a reversão.

Para o grupo SEM INSTRUÇÃO, o comportamento de escolha, antes da reversão, foi controlado pela iniqüidade de reforços: quando os participantes estavam em vantagem na distribuição de pontos, uma substancial preferência pela alternativa competitiva foi observada; caso contrário, quanto maior a desvantagem de pontos, menos acentuada a escolha por competição. Esses resultados corroboram aqueles relatados em outros estudos de competição (e.g., Dougherty \& Cherek, 1994; Matthews, 1979; Schmitt, 1987, 1998), como também em estudos de cooperação (e.g., de Farias, 2001; Schmitt \& Marwell, 1972; Shimoff \& Matthews, 1975), e sugerem que a iniqüidade desfavorável de reforços apresenta propriedades aversivas.

Após a reversão, a escolha por competição apresentou menor sensibilidade à iniqüidade de reforços. Os participantes que iniciaram o experimento com vantagem de pontos nas condições de iniqüidade e que preferiram quase exclusivamente a alternativa de competição nessas condições, não apresentaram alterações na escolha por competição após a reversão, a despeito do contato com as novas contingências (esse contato está ilustrado na Tabela 2, a qual indica que o número de pontos obtidos pelo Participante 2 após a reversão foi menor do que aquele obtido pelo parceiro, principalmente na condição 4:1). Os participantes que começaram com desvantagem de pontos, embora tenham apresentado um desempenho relativamente sensível às manipulações na iniqüidade de reforços após a reversão, não alcançaram os níveis mostrados pelos parceiros (e nem aqueles mostrados pelos ganhadores dos demais grupos) nas últimas duas condições. Esses resultados indicam que a sensibilidade do comportamento de escolha à reversão na iniqüidade de reforços foi influenciada pela história experimental de reforçamento e punição: quando a escolha por competição havia sido anteriormente reforçada, esse comportamento persistiu; quando essa escolha havia sido punida, a reversão na iniquiidade produziu reversão na escolha, mas não tão prontamente quanto seria esperado.

Efeitos comportamentais da história experimental têm sido amplamente divulgados na literatura. No estudo de Buskist \& Morgan (1987), por exemplo, após um treinamento inicial em esquema FI competitivo, dois pares de indivíduos foram expostos a um esquema FR não-competitivo e os outros dois pares a um esquema DRL não-competitivo. Em seguida, todos os pares retornaram ao esquema FI competitivo. Os resultados indicaram efeitos da história de reforçamento: a segunda exposição ao esquema FI competitivo gerou taxas mais altas que a primeira exposição, para os participantes treinados em FR, e taxas mais baixas para aqueles treinados em DRL (ver também Freeman \& Lattal, 1992; Weiner, 1969).

Efeitos de história são comumente relatados como transitórios. Isto é, com a mudança no ambiente, padrões comportamentais anteriormente selecionados persistem no novo ambiente mas, uma vez que o comportamento entra em contato com a contingência em vigor, os efeitos de contingências passadas tendem a se dissipar à medida que o controle pela contingência atual se desenvolve (Buskist \& Morgan, 1987; Freeman \& Lattal, 1992; Galizio, 1979; Sidman, 1960; Okouchi, 1999). Diversos aspectos parecem influenciar o grau de persistência dos efeitos de história. Um deles refere-se às propriedades discriminativas da contingência em vigor. Cerutti (1991) demonstrou que maior sensibilidade comportamental (ou, alternativamente, menor persistência dos efeitos de história) é observada quando os indivíduos são expostos à contingências que permitem um controle discriminativo preciso - o que, por sua vez, facilitaria o contato com a discrepância entre as contingências atual e passada - que quando são expostos à contingências que apresentam baixa discriminabilidade (ver também Torgrud, \& Holborn, 1990).

Os dados do presente estudo parecem contradizer essa afirmativa. A cada tentativa, um dos experimentadores registrava no quadro-negro os pontos ganhos por cada participante, bem como cada um dos participantes registrava em uma folha de papel seus próprios ganhos (alguns registravam também os ganhos de seu parceiro, embora não fossem solicitados a fazê-lo), o que permite afirmar, pelo menos a princípio, que as condições experimentais apresentavam propriedades discriminativas bastante precisas. Uma vez que o comportamento dos participantes entrava em contato com a mudança na contingência, caracterizada pela manipulação 
no grau de iniqüidade na alternativa de competição, logo na primeira tentativa em que escolhiam competir, seria esperado, com base nos argumentos de Cerutti (1991), que a reversão na iniqüidade de reforços fosse prontamente acompanhada por uma reversão na escolha por competição de cada participante em ambas condições de iniqüidade (2:1 e 4:1). Esse resultado, entretanto, não foi observado, possivelmente porque algum aspecto do procedimento pode ter comprometido a discriminabilidade da reversão. O relato pós-experimental de alguns participantes, por exemplo, sugere que a insensibilidade do comportamento de escolha após a reversão foi influenciada pelo risco de uma reversão adicional. Ou seja, a persistência do padrão de escolha desenvolvido antes da reversão (Participante 2) ou a mudança menor que a esperada (Participante 1) ocorreu, pelo menos em parte, porque a experiência prévia com uma reversão não sinalizada sugeria que poderia haver, a qualquer momento, uma nova reversão e, assim, um retorno às condições iniciais do experimento. Além disso, o possível controle discriminativo exercido pela informação sobre os pontos obtidos por cada participante pode ter sido reduzido pelo fato de que tal informação só era fornecida após cada participante ter efetuado sua escolha e, uma vez que as mudanças nas condições ocorriam muito freqüentemente (após cada seis tentativas), havia uma possibilidade que aquela informação não mais fosse fidedigna na tentativa seguinte, possibilidade essa que crescia no decorrer das tentativas de uma mesma condição.

Outra possível fonte de controle da insensibilidade à mudança ambiental refere-se à compatibilidade entre os padrões comportamentais anteriormente reforçados e as propriedades reforçadoras da nova contingência. Diversos estudos têm indicado que (a) a insensibilidade comportamental tende a ocorrer naquelas situações em que o responder continua produzindo consequiências reforçadoras após a mudança, e (b) quanto maior a frequiência de reforços disponíveis na nova contingência, mais acentuada a persistência do responder (Buskist, Bennett, \& Miller, 1981; Catania, Matthews, \& Shimoff, 1982; Galizio, 1979; Hayes, Brownstein, Zettle, Rosenfarb, \& Korn, 1986; Kaufman, Baron, \& Kopp, 1966; Newman, Buffington \& Hemmes, 1995). Resultados semelhantes foram observados no presente estudo: (a) os padrões de escolha apresentados por ambos os participantes continuaram gerando pontos após a reversão, o que contribuiu para a persistência do responder, e (b) a insensibilidade foi menos acentuada quando resultava em perdas dos reforços programados (Participantes 1).

A apresentação da INSTRUÇÃO PRECISA facilitou a aquisição de desempenhos compatíveis com as manipulações efetuadas na iniquiidade de reforços, para ambos participantes, tanto antes quanto após a reversão. Antes da reversão, foram observadas algumas semelhanças entre os dados apresentados pelos grupos com instrução precisa e sem instrução: (a) a escolha por competição variou como uma função inversa da iniqüidade desfavorável de reforços (Participante 1); e (b) foi observado um efeito teto, ou seja, uma vez que a condição 1:2, a primeira condição de iniquiidade apresentada, produziu escolha quase exclusiva por competição
(Participante 2), aumentos adicionais na escolha não foram observados com o aumento na iniquiidade favorável (condição 1:4).

Diferenças entre os dois grupos podem também ser apontadas. Primeiro, o desempenho do Participante 1 foi mais eficiente, no sentido de produzir uma maior redução na iniqüidade de reforços obtidos (ver Tabela 2), na presença de instrução precisa que na sua ausência, corroborando os resultados de diversos outros estudos (e.g., Ayllon \& Azrin, 1964; Danforth e cols., 1990; Dermer \& Rodgers, 1997; Galizio, 1979; Hayes e cols., 1986; Rosenfarb e cols., 1992), os quais indicam que instruções precisas facilitam a aquisição de desempenhos eficientes. Segundo, no grupo sem instrução, o Participante 2 mostrou porcentagens de escolha por competição mais altas do que o Participante 1 na condição de eqüidade, provavelmente em decorrência do treino nas condições 1:2 e 1:4 (lembrar que as condições de iniqüidade eram intercaladas com a condição de eqüidade e que os dados mencionados correspondem à média de quatro exposições à condição 1:1). No grupo com instrução precisa, por outro lado, os Participantes 1 e 2 apresentaram níveis semelhantes de escolha por competição, conforme ocorrido também em Matthews (1979), o que sugere que a instrução precisa sobre a distribuição de pontos a cada tentativa minimizou a influência mútua entre condições.

No estudo de Matthews (1979), os Participantes 1 e 2 apresentaram porcentagens de escolha por competição menos diferenciadas (75 e 87\% em 1:2, 60 e $89 \%$ em 1:4, respectivamente), antes da reversão, que os Participantes 1 e 2 do presente trabalho (35 e 97\% em 1:2, 30 e 100\% em 1:4, respectivamente). Considerando que a contingência de competição só entrava em vigor se ambos participantes escolhessem competir, Matthews argumentou que o Participante 1 apresentou uma escolha acentuada por competição mesmo estando em desvantagem de pontos porque dependia das escolhas do Participante 2, após a reversão, quando ele próprio passaria a ganhar mais pontos. Se o Participante 1 escolhesse sempre a alternativa individual antes da reversão (o que diminuiria a iniquidade de pontos obtidos entre os participantes), tornar -se-ia mais provável que o Participante 2 não escolhesse competir após a reversão. Embora essa situação de risco também tenha existido no presente estudo, o Participante 1 apresentou porcentagens baixas de escolha por competição, possivelmente em função das condições de reforçamento. Enquanto em Matthews os pontos eram trocados por dinheiro, de modo que tanto o Participante 1 quanto o Participante 2 recebiam reforços, no presente estudo os pontos eram trocados por fichas que permitiam a participação em um sorteio ao final do experimento. Dois aspectos desse último procedimento parecem explicar a diferença nos resultados dos dois estudos: (a) quanto maior o número de pontos ganhos no experimento, maior o número de fichas e, consequentemente, maior a chance de ganhar o sorteio; e (b) apenas um dos participantes poderia ganhar o sorteio de uma quantia em dinheiro (o outro nada recebia em termos monetários) e, assim, não era apenas uma questão de ganhar menos que o parceiro, mas de ganhar tudo ou não ganhar 
nada. Se o Participante 1 escolhesse competir antes da reversão, mas o Participante 2 não fizesse o mesmo após a reversão (como ocorreu no estudo de Matthews), suas chances no sorteio seriam minimizadas. Para evitar esse risco, portanto, o mais apropriado para o Participante 1 seria tentar reduzir a iniqüidade logo antes da reversão, o que foi feito por meio da escolha pela alternativa individual. Em suma, é provável que o sorteio tenha acentuado as propriedades aversivas da iniqüidade e, assim, gerado respostas de fuga/esquiva (escolhas pela alternativa individual).

Evidência adicional da redução dos efeitos da história experimental pode ser encontrada nos dados obtidos após a reversão. Enquanto na ausência de instrução os participantes continuaram apresentando padrões de escolha semelhantes após a reversão, na presença da instrução precisa as escolhas por competição prontamente se inverteram de modo a se ajustar às novas contingências. Considerando as observações de Cerutti (1991) sobre a relação direta entre discriminabilidade e sensibilidade comportamental, é viável afirmar que a instrução precisa potencializou as propriedades discriminativas de cada contingência programada o que, por sua vez, contribuiu para o estabelecimento do responder apropriado (é possível que a exposição repetida do grupo sem instrução a reversões adicionais contribuísse para aumentar a discriminabilidade das manipulações efetuadas $\mathrm{e}$, assim, gerasse um desempenho semelhante àquele apresentado pelo grupo com instrução precisa). Por ser fornecida no início da tentativa, a instrução precisa eliminava o risco de uma reversão não sinalizada naquela tentativa, e por indicar exatamente quando a reversão ocorreria, eliminava a possibilidade de reversões adicionais intra-sessão (embora o participante não soubesse exatamente se haveria outra sessão ou não e, consequentemente, se ocorreriam outras reversões ao longo do experimento, pelo menos naquele dia ele sabia que só ocorreria uma reversão e quando a mesma ocorreria).

Os resultados desse grupo, quando comparados com aqueles apresentados pelo grupo sem instrução, sugerem que a informação sobre a reversão ou, alternativamente, sobre a possibilidade do estabelecimento de eqüidade no decorrer das condições, parece ter exercido maior controle sobre o comportamento de escolha que a informação sobre a distribuição de pontos entre os participantes a cada tentativa. Além disso, é importante considerar que a história de reforçamento do comportamento de seguir instrução, estabelecida antes da reversão, provavelmente contribuiu para aumentar a probabilidade desse comportamento após a reversão (DeGrandpre \& Buskist, 1991; Galizio, 1979; Raia, Shillingford, Miler \& Baier, 2000; Newman e cols., 1995).

No grupo com INSTRUÇÃO IMPRECISA, a alternativa de competição ocorreu mais freqüentemente que nos demais grupos, antes e após a reversão, tendo ambos participantes apresentado porcentagens similares de escolha por competição mesmo nas condições de alta iniqüidade. A comparação dos desempenhos dos dois grupos com instrução sugere que o grau de precisão da instrução afetou diferencialmente o responder: enquanto o uso da instrução precisa produziu mudanças comportamentais compatíveis com as manipulações efetuadas na iniqüidade de reforços, o uso da instrução imprecisa gerou insensibilidade comportamental a despeito do contato extensivo com tais manipulações (ver Dixon, Hayes \& Aban, 2000; Hackenberg \& Joke, 1994; Hayes e cols., 1986; Martinez \& Ribes, 1996). Dougherty e Cherek (1994) também encontraram insensibilidade com o uso de instruções que faziam referência à tarefa de escolha entre as alternativas de competição e individual, mas não indicavam a probabilidade do reforço em vigor ao longo das condições (ver também Danforth e cols., 1990; DeGrandpre \& Buskist, 1991; Newman e cols., 1995).

Uma questão que se segue é "por que os participantes com desvantagem na distribuição de pontos escolheram prioritariamente a alternativa de competição?’. A instrução imprecisa, ao afirmar que ora o participante ganharia mais pontos, ora ganharia menos pontos, claramente sugeria que reversões não sinalizadas poderiam ocorrer a qualquer momento. Enquanto a possibilidade de reversões não sinalizadas adicionais só passou a controlar o comportamento de escolha do grupo sem instrução após a experiência com a primeira reversão, e não afetou as escolhas do grupo com instrução precisa já que essa instrução indicava que só haveria uma reversão na sessão e quando a mesma ocorreria, para o grupo com instrução imprecisa tal possibilidade controlou as escolhas dos participantes logo a partir da primeira tentativa com iniquiidade de reforços. Ou seja, a iniqüidade desfavorável poderia, a qualquer momento, tornar-se favorável $\mathrm{e}$, caso o participante escolhesse a alternativa individual quando essa reversão ocorresse, diminuiria suas chances no sorteio. Dessa forma, o mais apropriado para cada participante seria escolher a alternativa de competição. É importante lembrar que o risco do parceiro não competir após a reversão, presente no grupo com instrução precisa, foi reduzido na presença da instrução imprecisa já que as escolhas deste também estavam sob o controle da possibilidade de reversões adicionais. Outra estratégia para evitar iniqüidade desfavorável consistiria em escolher exclusivamente a alternativa individual ao longo do experimento mas, nesse caso, o participante estaria eliminando também a possibilidade de estabelecer iniqüidade favorável. Além disso, se as outras duplas não adotassem essa mesma estratégia, ganhariam mais pontos e teriam mais chances no sorteio.

A escolha quase exclusiva por competição no decorrer do experimento implicava em iniqüidade desfavorável naquelas ocasiões em que o parceiro passava a ganhar mais, o que sugere que os indivíduos podem se expor ocasionalmente à iniqüidade desfavorável quando há possibilidade de reestabelecer a eqüidade (ou aumentar a iniqüidade favorável). Resultados comparáveis foram obtidos em um estudo sobre escolha entre trabalho cooperativo versus trabalho individual (Matthews, 1977). É possível afirmar, portanto, que a escolha acentuada por competição, observada no grupo com instrução imprecisa, tanto pode indicar insensibilidade a mudanças momentâneas na iniqüidade de reforços, quanto sensibilidade a contingências atrasadas, a saber, a provável eqüidade. 
A análise dos pontos obtidos revela que, ao final do experimento, os três grupos apresentaram eqüidade de pontos entre os Participantes 1 e 2. Conforme indicado anteriormente, essa eqüidade foi obtida por meio de processos comportamentais diferenciados entre os grupos. Considerando apenas o comportamento dos perdedores, no grupo com instrução imprecisa, a equiidade resultou da escolha predominante por competição; no grupo com instrução precisa, da relação inversa entre escolha e iniqüidade desfavorável; e no grupo sem instrução, de ambas as estratégias. Conseqüentemente, para os grupos sem instrução e com instrução imprecisa, a equiidade final foi produzida pelo balanceamento entre iniquiidade favorável ao Participante 2 antes da reversão e favorável ao Participante 1 após a reversão; para o grupo com instrução precisa, por outro lado, a eqüidade ocorreu em todas as condições experimentais. Dentre os três grupos, o grupo com instrução precisa foi o que apresentou a maior porcentagem de escolhas pela alternativa individual (principalmente nas condições 1:4 e 4:1), o menor número total de pontos (lembrar que o número médio de pontos na alternativa individual era sempre menor que aquele na alternativa de competição), e a maior eqüidade de pontos entre os participantes ao longo das condições. Isso indica que, no grupo com instrução precisa, o perdedor optou pela redução na iniqüidade de pontos, mesmo que isso implicasse em redução no total de pontos obtidos. Esses resultados sugerem que a instrução precisa sobre a reversão potencializou as funções aversivas da iniqüidade de pontos, produzindo estratégias mais eficientes de fuga/esquiva da iniquiidade que o treino sem instruções ou com instruções imprecisas.

\section{Referências}

Ayllon, T. \& Azrin, N. H. (1964). Reinforcement and instructions with mental patients. Journal of the Experimental Analysis of Behavior, 7, 327-331.

Baum, W. M. (1999). Compreender o behaviorismo: ciência, comportamento e cultura. Porto Alegre: Artmed. (Trabalho original publicado em 1994)

Buskist, W., Barry, A., Morgan, D. \& Rossi, M. (1984). Competitive fixed-interval performance in humans: Role of "orienting" instructions. Journal of the Experimental Analysis of Behavior, 34, 241-257.

Buskist, W. F., Bennett, R. H. \& Miller, H. L. (1981). Effects of instructional constraints on human fixed-interval performance. Journal of the Experimental Analysis of Behavior, 35, 217225.

Buskist, W. F. \& Morgan, D. (1987). Competitive fixed-interval performance in humans. Journal of the Experimental Analysis of Behavior, 47, 145-158.

Buskist, W. F. \& Miller, H. L., Jr. (1986). Interaction between rules and contingencies in the control of human fixed-interval performance. Psychological Record, 36, 109-116.

Catania, A. C., Matthews, B. A. \& Shimoff, E. (1982). Instructed versus shaped human verbal behavior: Interactions with nonverbal responding. Journal of the Experimental Analysis of Behavior, 38, 233-248.
Cerutti, D. T. (1991). Discriminative versus reinforcing properties of schedules as determinants of schedule insensitivity in humans. The Psychological Record, 41, 51-67.

Danforth, J. S., Chase, P. N., Dolan, M., \& Joyce, J. H. (1990). The establishment of stimulus control by instructions and by differential reinforcement. Journal of the Experimental Analysis of Behavior, 54, 97-112.

de Farias, A. K. C. R. (2001). Regras e iniqüidade entre reforços: influência sobre a escolha entre cooperação e competição. Dissertação de Mestrado não publicada. Universidade de Brasília, Brasília, DF.

DeGrandpre, R. J. \& Buskist, W. F. (1991). Effects of accuracy of instructions on human behavior: Correspondence with reinforcement contingencies matters. The Psychological Record, 41, 371-384.

Dermer, M. L. \& Rodgers, J. G. (1997). Schedule control over following instructions comprised of novel combinations of verbal stimuli. The Psychological Record, 47, 243-260.

Dixon, M. R. \& Hayes, L. J. (1998). Effects of differing instructional histories on the resurgence of rule-following. The Psychological Record, 48, 275-292.

Dixon, M. R., Hayes, L. J., \& Aban, I. B. (2000). Examining the roles of rule-following, reinforcement, and preexperimental histories on risk-taking behavior. Psychological Record, 49, 687-705.

Dougherty, D. M. \& Cherek, D. R. (1994). Effects of social context, reinforcer probability, and reinforcer magnitude on human's choices to compete or not to compete. Journal of the Experimental Analysis of Behavior, 62, 133-148.

Freeman, T. J. \& Lattal, K. A. (1992). Stimulus control of behavioral history. Journal of the Experimental Analysis of Behavior, 57, 5-15.

Galizio, M. (1979). Contingency-shaped and rule-governed behavior: Instructional control of human loss avoidance. Journal of the Experimental Analysis of Behavior, 31, 53-70.

Hackenberg, T. D. \& Joker, V. R. (1994). Instructional versus schedule control of humans' choices in situations of diminishing returns. Journal of the Experimental Analysis of Behavior, 62, 367-383.

Hake, D. F. \& Vukelich, R. (1972). Classification and review of cooperation procedures. Journal of the Experimental Analysis of Behavior, 18, 333-343.

Hayes, S. C., Brownstein, A. J., Zettle, R. D., Rosenfarb, I. \& Korn, Z. (1986). Rule-governed behavior and sensitivity to changing consequences of responding. Journal of the Experimental Analysis of Behavior, 45, 237-256.

Kaufman, A., Baron, A. \& Kopp, R. E. (1966). Some effects of instructions on human operant behavior. Psychonomic Monograph Supplements, 1, 243-250.

Keller, F. S. \& Schoenfeld, W. N. (1971). Principios de Psicologia. São Paulo: Editora Herder. (Trabalho original publicado em 1950)

Madden, G. J., Chase, P. N. \& Joyce, J. H. (1998). Making sense of sensitivity in the human operant literature. The Behavior Analyst, 21, 1-12.

Martinez, H., \& Ribes, E. (1996). Interactions of contingencies and instructional history on conditional discrimination. The Psychological Record, 46, 301-318. 
Matthews, B. A. (1977). Magnitudes of score differences produced within sessions in a cooperative exchange procedure. Journal of the Experimental Analysis of Behavior, 27, 331-340.

Matthews, B. A. (1979). Effects of fixed and alternated payoff inequity on dyadic competition. The Psychological Record, 29, 329-339.

Newman, B., Buffington, D. M. \& Hemmes, N. S. (1995). The effects of schedules of reinforcement on instruction following. The Psychological Record, 45, 463-476.

Okouchi, H. (1999). Instructions as discriminative stimuli. Journal of the Experimental Analysis of Behavior, 72, 205-214.

Raia, C. P., Shillingford, S. W., Miller, H. L. Jr., \& Baier, P. S. (2000). Interaction of procedural factors in human performance on yoked schedules. Journal of the Experimental Analysis of Behavior, 74, 265-281.

Rosenfarb, I. S., Newland, C., Brannon, S. E. \& Howey, D. S. (1992). Effects of self-generated rules on the development of schedule-controlled behavior. Journal of the Experimental Analysis of Behavior, 58, 107-121.

Schmitt, D. R. (1984). Insterpersonal relations: Cooperation and competition. Journal of the Experimental Analysis of Behavior, 42, 377-383.

Schmitt, D. R. (1987). Interpersonal contingencies: Performance differences and cost-effectiveness. Journal of the Experimental Analysis of Behavior, 48, 221-234.
Schmitt, D. R. (1998). Effects of consequences of advice on patterns of rule control and rule choice. Journal of the Experimental Analysis of Behavior, 70, 1-21.

Schmitt, D. R. \& Marwell, G. (1972). Withdrawal and reward reallocation as responses to inequity. Journal of Experimental Social Psychology, 8, 207-221.

Shimoff, E. \& Matthews, B. A. (1975). Unequal reinforcer magnitudes and relative preference for cooperation in the dyad. Journal of the Experimental Analysis of Behavior, 24, 1-16.

Sidman, M. (1960). Táticas da pesquisa cientifica. São Paulo: Editora Brasiliense.

Skinner, B. F. (1969). Contingencies of reinforcement: A theoretical analysis. New York: Appleton-Century-Crofts.

Torgrud, L. J., \& Holborn, S. W. (1990). The effects of verbal performance descriptions on nonverbal operant responding. Journal of the Experimental Analysis of Behavior, 54, 273-291.

Weiner, H. (1969). Controlling human fixed-interval performance. Journal of the Experimental Analysis of Behavior, 56, 489504.

Wulfert, E., Greenway, D. E., Farkas, P., Hayes, S. C. \& Dougher, M. J. (1994). Correlation between self-reported rigidity and rul-governed insensitivity to operant contingencies. Journal of Applied Behavior Analysis, 27, 659-671.

Recebido em 09.05.2001

Primeira decisão editorial em 07.12.2001

Versão final em 14.05.2002

Aceito em 14.05.2002 